\title{
Research on Selectivity of Co-processing Protection Methods for Ship Distribution Network Based on Communications
}

\author{
Huang Jing, He Huiying, Zhou Shiwan, Zhang Tao* \\ Electrical Engineering Department, School of Electrical Engineering, Naval University of Engineering, Wuhan, China \\ Email address: \\ 836148867@qq.com (Zhang Tao) \\ *Corresponding author
}

\section{To cite this article:}

Huang Jing, He Huiying, Zhou Shiwan, Zhang Tao. Research on Selectivity of Co-processing Protection Methods for Ship Distribution Network Based on Communications. Journal of Electrical and Electronic Engineering. Vol. 4, No. 2, 2016, pp. 6-12. doi: $10.11648 /$ j.jeee.20160402.11

Received: January 21, 2016; Accepted: March 11, 2016; Published: April 7, 2016

\begin{abstract}
Relaying system is a distributed discrete structure, each protector and detection unit is distributed in logic and physics. In this text, the authors propose a selective protection method of ship distribution network based on the strategy of communication coordinate, designing the protector to intelligent structure which has the function of fault current detection, calculation of current rising rate, communication and coordination processing. For communication coordinated strategy in ship power distribution network, the application of selective protection research, to improve the effectiveness of the selective protection of ship power distribution network is of great significance.
\end{abstract}

Keywords: Power Distribution Network, Selective Protection, Collaborative Strategy, Communication

\section{Introduction}

With the increasing capacity of ship power system, the structure is increasingly complex, Higher request is made to the relay protection of ship power system [1-4]. Ship distribution series is increasing, upper and lower level protectors often trip at the same time when appearing large short circuit current [5-7]. For promising the safe operation of ship distribution network, for completing well selective protection, for improving the electric energy quality of ship power system and maintaining the continuity of power supply, it has great significance to carry out the research of selective protection of intelligent ship distribution network. [8-12]

In this text, we propose a selective protection method of ship distribution network based on the strategy of communication coordinate, designing the protector to intelligent structure which has the function of fault current detection, calculation of current rising rate, communication and coordination processing. Analysis principle of fault location based on communication and coordination, proposing the selective promotion strategy based on communication and coordination, giving the coordinate acting relationship of protector and general principle. Giving a specific coordination strategy of each level protector aimed at distribution network of three levels. Completing the design of the structure of ship distribution system protector based on communication cooperation strategy, completing setting up hardware platform. The experimental result tested the effectiveness of communication cooperation strategy.

\section{Analysis of Short Circuit Fault Location Principle Based on Multi-computer Communication}

To combine the relay protection system, in this paper, each of the protection system to protect device designed to the corresponding intelligent node, this intelligent node have detection function, fault protection setting function, communication function and protection function. Detection function and protection setting calculation is protector uses current sensor for detecting current flows through the protection of the installation points and detect the current through $\mathrm{A} / \mathrm{D}$ converter to intelligent module, intelligent 
modules completed to calculate current rising rate and analysis and fault judgment; Use protector of communication function will determine the results and their own protector status is sent to the superior protector, at the same time receive lower judgment results and motion state, intelligent module of protective device integrated protector of higher and lower judgment results with their own judgment to make fault location and remove action, all protectors complete selective protection together, implementing the detection and selective protection of the distribution network fault.

The purpose of multi-computer communication is using serial communication function of SCM to send the determine results and control action of all levels protectors to the superior protector. Using current rising rate and current setting to realize fault current distributed determine and quickly setting, through the communication coordination to realize fault location and selective removal [12-13]. In typical radiant tertiary distribution network as an example, the protector as per level of protection from the machine directly, the whole distribution network form the main type of communication, as shown in Fig. 1.

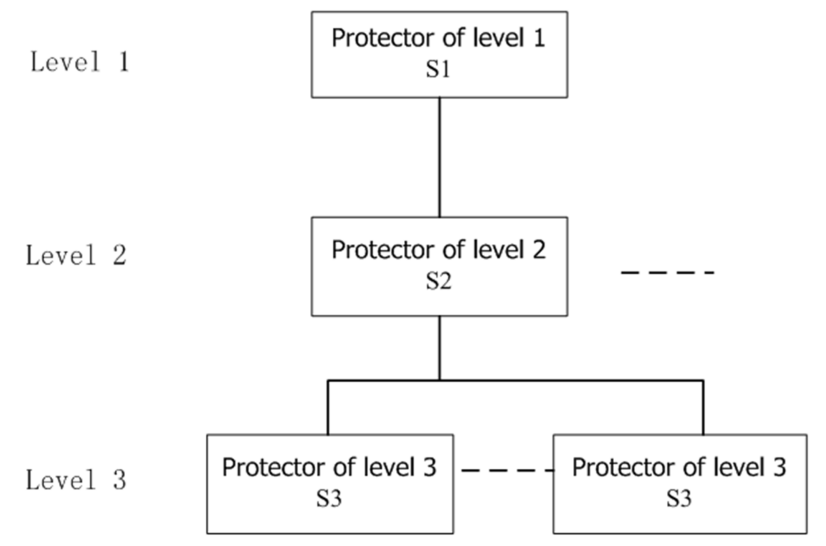

Fig. 1. Three level SCM communication model.
In communication, assign a unique address to each protector first. And then define the communication information for three types of data: the first data status is value "2", expressing determination results for short circuit fault; the second data status is value "1", expressing the determination results for no short circuit fault; the third state of data is value " 0 ", expressing not to receive data protection at a lower level. All communication data from down to sent to the superior device.

Completed defines communication data between protector, achieve short circuit fault location with communication data. In Fig. 1, third level protector is located in the end of the distribution network, as long as protector detected the short trouble, identified as the terminal short circuit protector. Secondary protector detected the fault and received triple protector data, fault occurs below the level 3 protector if the data is " 2 "; short circuit fault occur between secondary protector and tertiary protector if the data is " 1 "; If the data is " 0 ", that means first protector has not accept from secondary protector, that also means secondary protector is damaged, so short fault appear below the first protector.

\section{Selective Protection Based on Communication Coordination Strategy}

All these researches are aimed at ship $\mathrm{AC}$ power distribution network, built on ship AC power distribution network topology system. As a result, analysis the ship AC power distribution network topology system is needed. Typical 3 level ship radiation power distribution network in Fig. 2 as an example, state in detail the distributed short fault decide and communication cooperate strategy ideology.

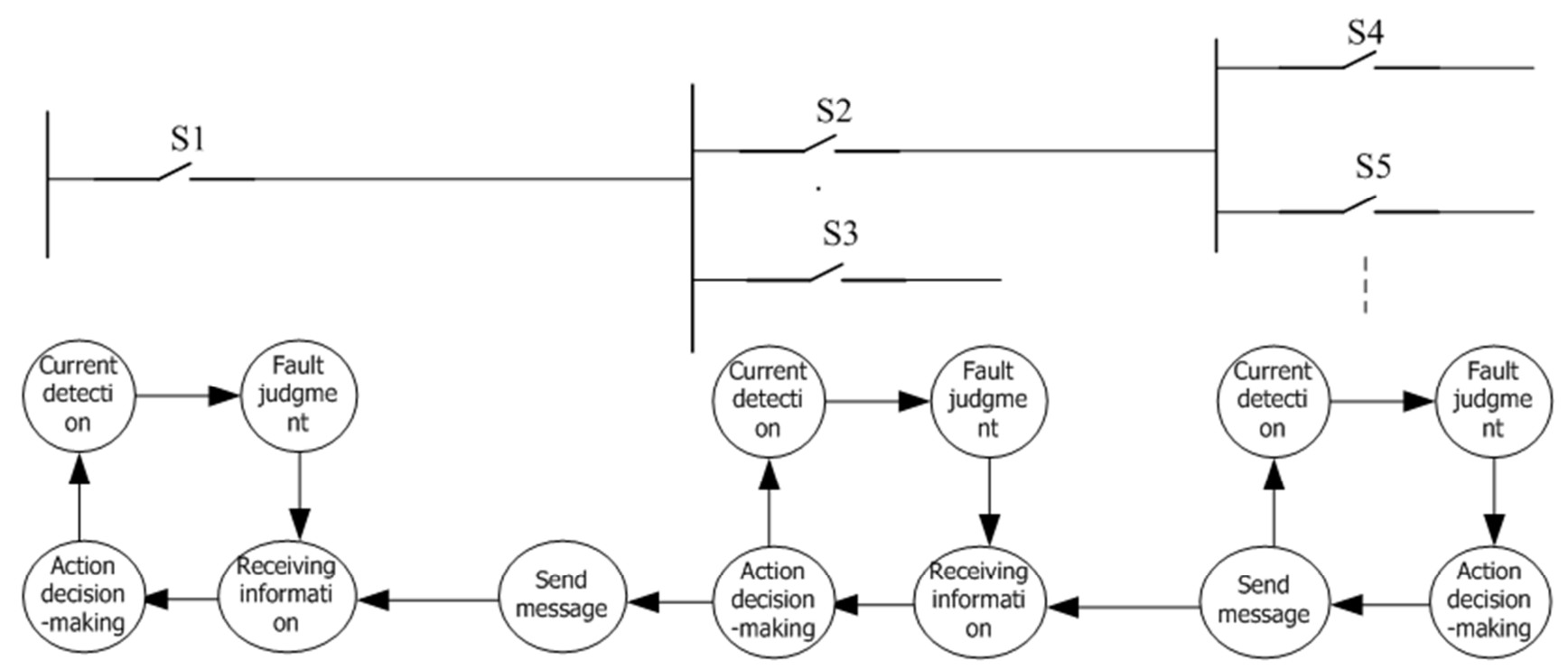

Fig. 2. Three level ship radiant power distribution network. 
Shows as the figure, protector sends the judge results to superior protector through communication, accept judge results from subordinate protector at the same time, complete current detection, fault judgment and fault location. In that way, protector act or not next, accomplish selective protection or not are depend on communication cooperation strategy, that means for accomplishing selective protection, the important is the communication cooperation strategy of each level of protector.

Action dependence of each protector mainly include the two terms: The first is detection and judgment results of the protector itself; the second is data accepted in subordinate protector. The principle of protector: detect on the same level, calculation and short fault has judged, accept judgment result from subordinate protector, according to the previous section fault location principle, decide whether the protector to remove faults at the corresponding level. If the data received from lower level protector shows appearing short fault, protector at the corresponding level will not act; if the data received from lower level protector shows do not appear short fault, protector at the corresponding level will act to remove the fault.

Here is coordinated strategy of each level protector in three level distribution network.

Coordinated strategy of three level protector: For three level protector S4, S5, S6, S7 located at the protection position in the end of distribution network, when judged to be short fault according to current rising rate, protector will act to remove fault directly, and send judgment result and the action state of protector to superior protector.

Coordinated strategy of second level protector: Protector S2 detected short fault itself, also need to receive judgment result from S4 and S5, then completing fault location according to fault location theory. Making action decision combine detection and judgment result itself, and send the detection and judgment result and action decision to first level protection. Action strategy of second level protector as showed in table 1.

Table 1. Protector S2 action decisions.

\begin{tabular}{lll}
\hline Information of S4 and S5 & $\mathbf{0 0 , 0 1 , 1 0 , 1 1}$ & $\mathbf{1 2 , 2 1 , 2 2}$ \\
\hline Determine results of s2 & Action & Inaction \\
\hline Yes &
\end{tabular}

Corresponding strategy of first level protection: First level protector S1 detected short fault, and receive judgment result from protector $\mathrm{S} 2$ and $\mathrm{S} 3$, making action strategy combine the information received, as shown in Table 2.

Table 2. First level protector action decisions.

\begin{tabular}{llll}
\hline & Information of S2 and S3 & $\mathbf{0 0 , 0 1 , 1 0 , 1 1}$ & $\mathbf{1 2 , 2 1 , 2 2}$ \\
\cline { 1 - 3 } Determine results of $\mathbf{s 1}$ & Action & Inaction \\
\hline Yes
\end{tabular}

\section{Design of Protector Structural}

Detection and protection setting calculation function is protector detect the current flow through protection mounting point, the current detected flow through $\mathrm{A} / \mathrm{D}$ converter will sent to intelligent module, intelligent module completing calculating and analysis the current rising rate received and making fault judgment; Using communication function, protector send the judgment result and action state to superior protector, and receive judgment result and action state from lower level protector at the same time, intelligent module of protector combines superior and subordinate judgment result and judgment result of itself, making fault location and removing action, disposing cooperate and the realize selective protection. Integral structural of protector is shown in Fig. 3.

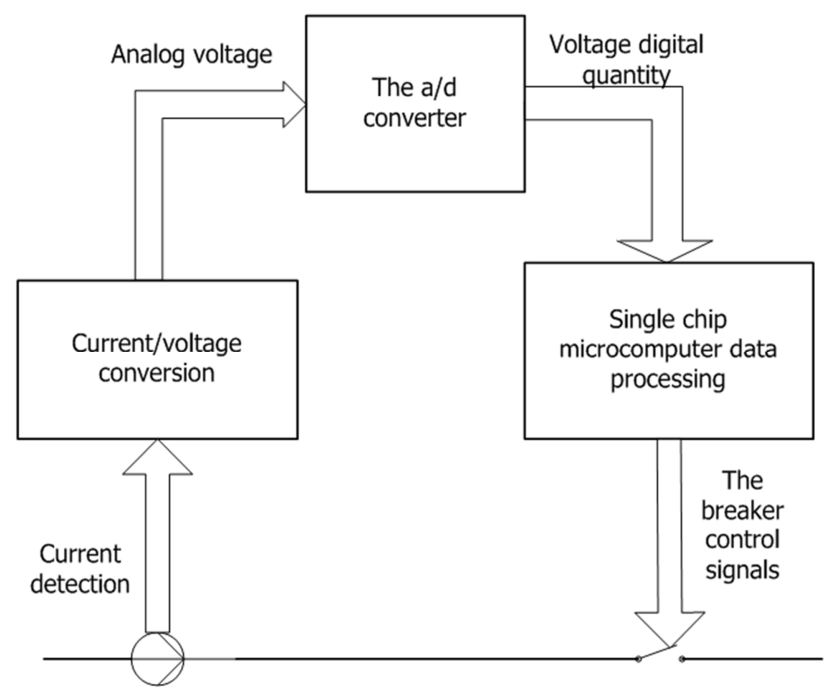

Fig. 3. The whole structure of protector.

Using hall current sensor to collect current flow through protector uninterrupted, A/D converter transform the current collected from sensor to digital signal and transport to SCM, SCM undertake all the function of intelligent module, completes data calculation, fault setting, communication processing, fault remove and output control. In the whole process, sampling frequency, conversion accuracy, conversion rate and coordinate strategy are main content to realize selective protection. Then choosing device aimed at the need of each module.

\section{(1) Current Detection Module}

Current detection module mainly converts the current flow through protector in ship distribution network to small-signal current that can be read, then convert the current to voltage signal. This text mainly aimed at detecting and protecting short fault, the current flow through protection is bigger when short-circuited, for meeting the require of detection and control, also do not affect the work of distribution network, we choosing hall current sensor to detect the current in distribution network. The voltage signal detected from hall current sensor is analog quantity, it cannot be disposed by SCM directly, converting the analog quantity to digital quantity that can be disposed by SCM. This text is mainly 
aimed at protecting the short fault in ship alternating current power system, the voltage signal detected is AC signal, and having a high requirement for converting accuracy.

\section{(2) SCM Processing Module}

For meeting the requirement of calculation setting, rapidly fault judgment and fast communication in devices, SCM processing module choose 32-bit processor ARM SCM LPC1768.ARM SCM integrate all kinds of modules, possess many distinctive characteristics: First, processing rapidly, powerful, bigger storage capacity and convenient for client upgrade and extension and transformation; Second, highly safe, the data is not easy to lose. Third, ARM SCM bring their own network communication port, it can combine peripheral devices and realize network communication. Fourthly, it can download and upgrade from network directly, maintain conveniently.

(3) Multi-computer Communication Based on CAN Bus

CAN bus support serial communication network of distributed control and real-time control, main feature: (1)
CAN bus can use multi-communication, it is flexible and convenient; according to priority to bus access. (2) Using non-destructive bus verdict technology, high priority level node can send data preferentially, low priority level node stop sending data when sending. (3) It can meet the requirement of point-to-point and one-to-many sending and receiving data. (4) Far transmitting range, communication rate reach up to 1Mbps. (5) It uses data frame structure, possessing CRC detection, anti-interference capability of the data is high, low error rate. (6) It can remove connection automatically, make sure that other operation will not be disturbed when error seriously.

For realizing the judgment result of high level and low level protector can be communicated rapidly, meeting the need of protector one-to-many communication coordinate processing. This text chooses CAN bus that possessing multi-communication, higher anti-interference performance and higher real-time performance to complete multi-communication among protector.

\section{Experiment Confirm of Selective Protection Method Based on Communication Coordinate Strategy}

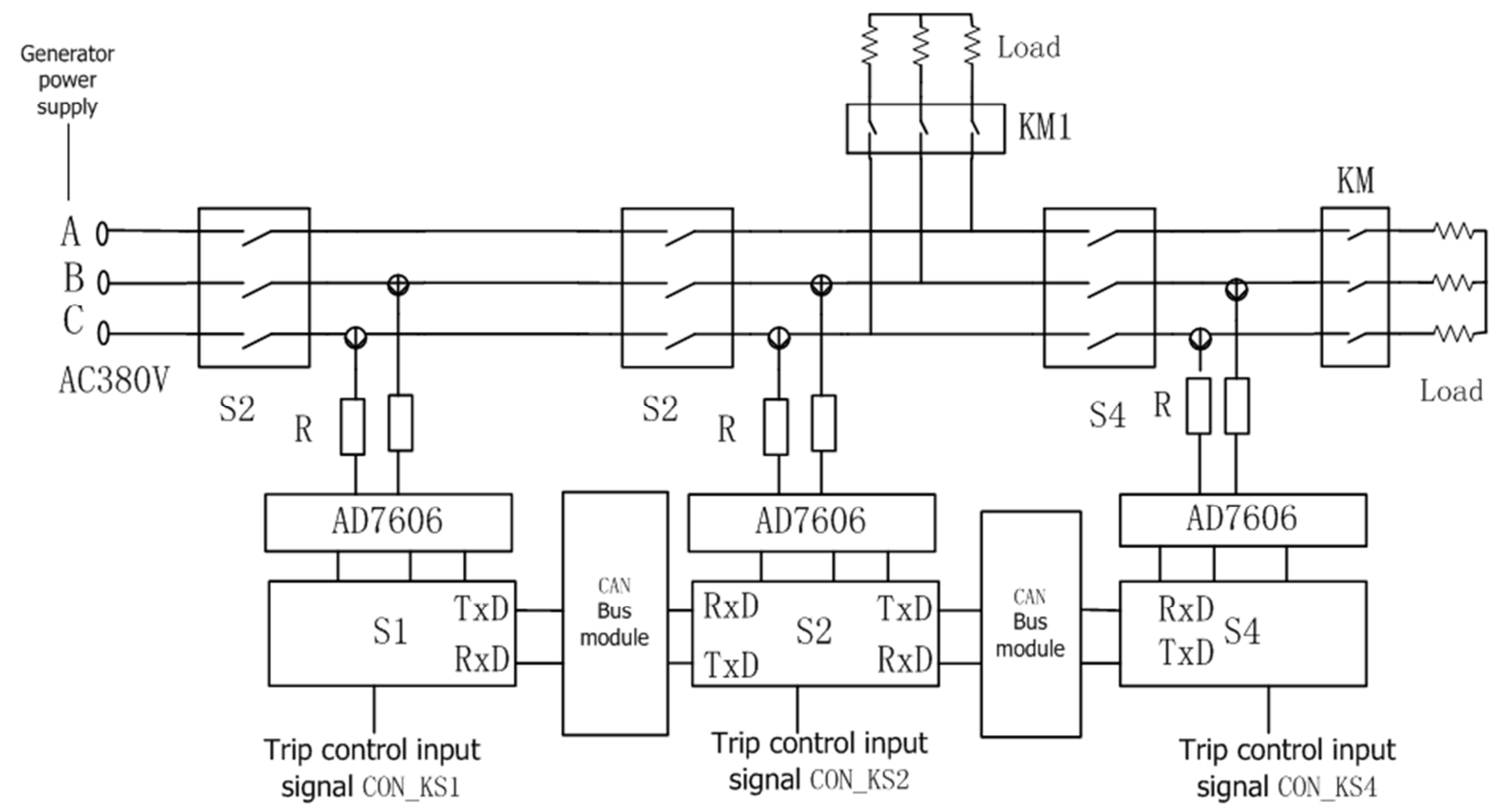

Fig. 4. Circuit of selective protection system.

For realizing selective protection of ship distribution network, simulating the method in this text of selective protection method based on communication coordinate strategy, in this chapter, we process the experiment confirm. Experiment purposes: Confirming whether the protection method based on communication coordinate strategy can realize selective protect or not, the rapidity of communication coordinate strategy among different protectors. Experiment is divided into three part: short current obtain, A/D converting and removing short fault selectively by communication method.

\subsection{Experimental Circuit}

Circuit of two and three level protector system is shown in fig. 4, in the Figure, S2 and S4 are the representations of two and three level protectors, KM is short circuit access control contactor which mainly controlling sudden load short fault. Protection system uses current sensor to collect current data, using four current sensor to collect the current of $\mathrm{B}$ phase and $C$ phase, using the formula $i_{a}=-\left(i_{b}+i_{c}\right)$ to calculate current of A phase, the type of current sensor: LMK (BH) - $0.66 \mathrm{CT}$, transformation ratio is $900 \mathrm{~A} / 5 \mathrm{~V}, \mathrm{~A} / \mathrm{C}$ transfer resister is 
$10 \Omega$.Generator set is single simulate synchronous generator, capacity: $5 \mathrm{kVA}$, nominal voltage: $380 \mathrm{~V}$, nominal current: 12.55A. For limited experiment condition, synchronous generator cannot conduct short-circuit experiment repeatedly, in this experiment, we simulate short-circuit by sudden loading big load. Using the similarities between short current within a quarter periods to simulate short current, testing the function of selective protection system based on current rising rate and communication coordinate strategy.

System working state before short fault:S4 and S5 master contactor switch on, contactor KM switch off, the current flow through protector S2 and S4 is zero, current detected by four sensor are all zero.

Working state when in short-circuit: KM switching on, switch in short fault, short-circuit current flow through protector S2 and S4, all the four sensor detected short-circuit current. S2 and S4 remove the fault according to communication coordinate strategy. The physical map of selective protection is shown in Fig. 5.

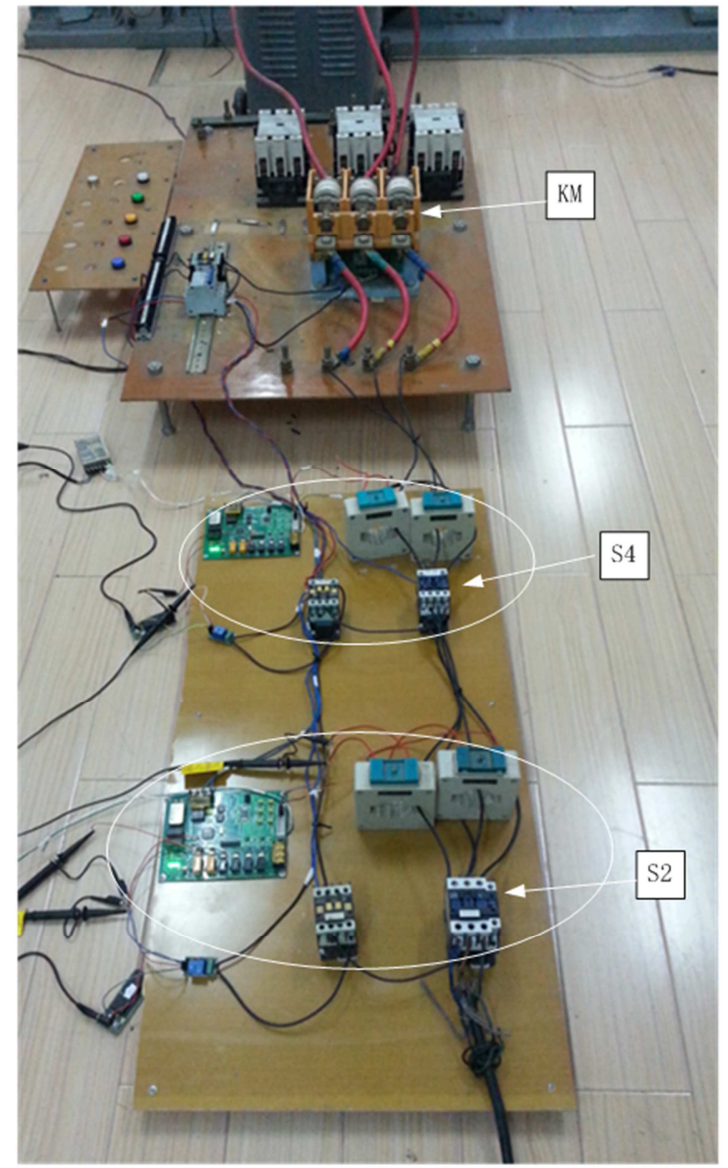

Fig. 5. Physical map of selective protection system.

\subsection{Experimental Data and Analysis}

In the experiment, it is no-load before short-circuit, current flow through hall current sensor is 0 ; Current flow through hall current sensor is short-circuit current after short-circuit. For testing the selective protection method based on communication coordinate strategy in this text, next simulating and analysis from different condition.

(1) Simulation: The selectivity and effectiveness of protection system when the end of transmission line appears short-circuit fault.

When appearing short fault in the end of transmission line, the waveform of short fault communication of two and three level protector short fault communication and S4 removing fault is shown in Fig. 6. Four waveform, 1) is current waveform of A phase, 2) is communication state of two and three level protector, 3 ) is release action control signal of three level protector S4. 4) is release action control signal of third level protector $\mathrm{S} 2$.

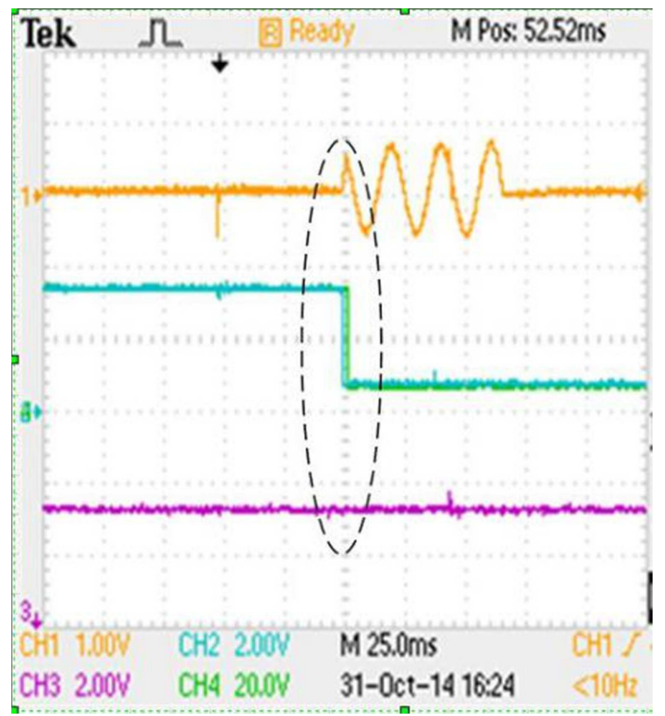

(a) Waveform of fault current excision

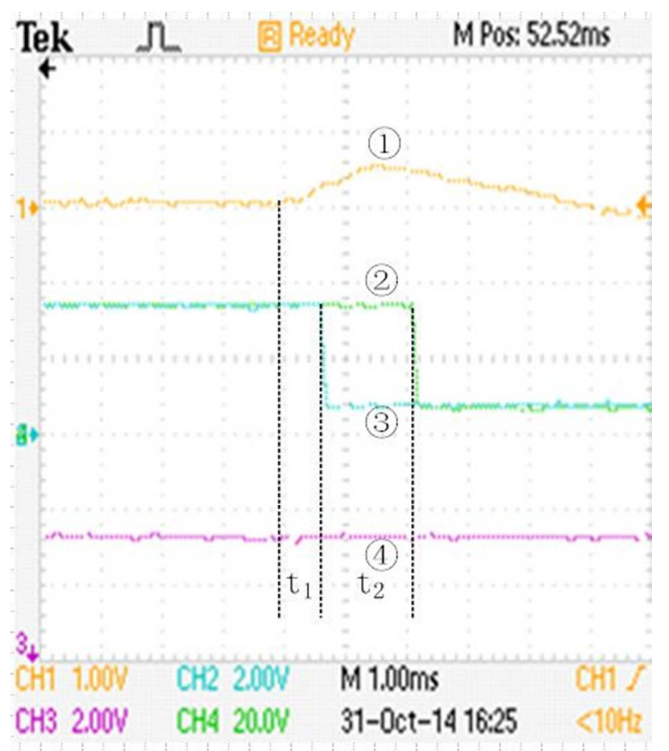

(b) Partial enlarged drawing

Fig. 6. Waveform of protector removing short fault.

It can be seen from " $\mathrm{A}$ " phase current waveform, the peak value of current is $20.42 \mathrm{~A}$, initial current rising rate up to $15.70 \mathrm{~A} / \mathrm{ms}$.

In Fig. 6(b), $t_{1}$ is the interval time from initial moment to the 
time third level protector S4 output release act control signal, it is about $400 \mu \mathrm{s}$. Within $\mathrm{t} 1$, the second and third level protector S2 and S4 completed current detection and fault judgment according to rising rate at the same time, the third level protector outputs release action control signal directly according to action strategy, touch off the breaker to switch off. $t_{2}$ is the interval time from $S 4$ outputs release action and control signal to the second and third level protector S2 and S4 completed communicate, it is about $1 \mathrm{~ms}$. S2 reach judgment result of different action after communication according to cooperation strategy, thus the fourth waveform in Fig. which shows release do not output action and control signal do not appear lower jump.

This implies that protection system completed fault detection, calculation setting, communication cooperation judgment and release control the signal input, tested the accuracy and effectiveness of protection system communication cooperation when appear ending short-circuit. Because the chosen protector release executes some responses slowly in experiment, short current cannot be switch-off immediately after release input control signal, this lead to switch-off the short current after $75 \mathrm{~ms}$, but thinking that we mainly research selective protection strategy, action speed of the switches will not affect the test of protection strategy.

(2) Test: The selective and effectiveness of protection system when second and third level protector appears short fault.

The waveform of second level protector remove short fault is shown in Fig. 7, the four waveform in Fig. top to bottom, the first is waveform of A phase, the second is release control and action signal output from second level protector S4, the third is release control and action signal output from second level protector $\mathrm{S} 2$, the fourth is waveform of second and third level protector communication state.

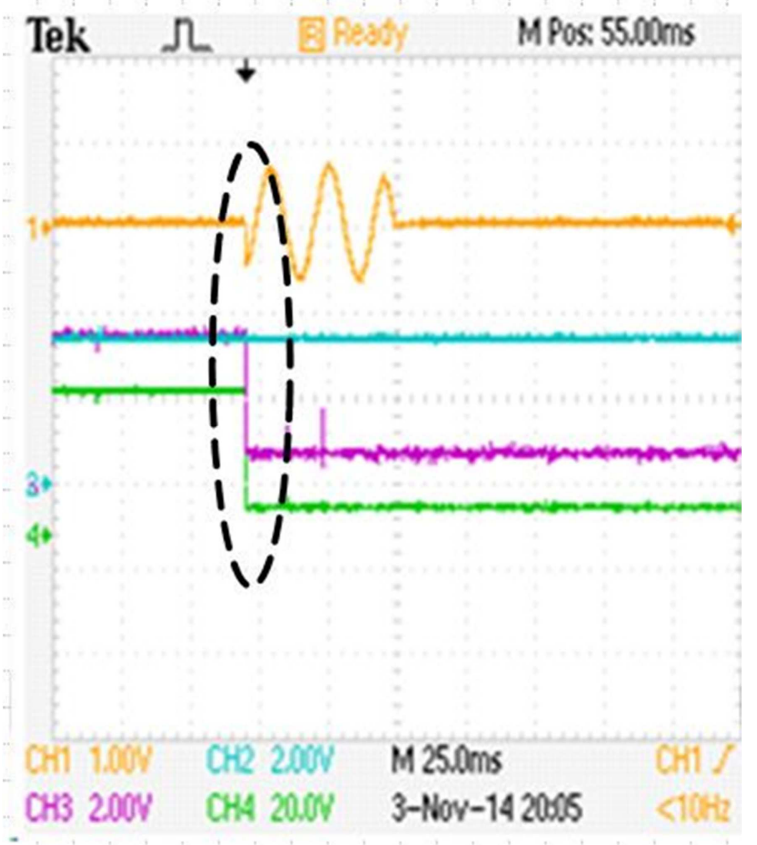

(a) Waveform of fault current excision

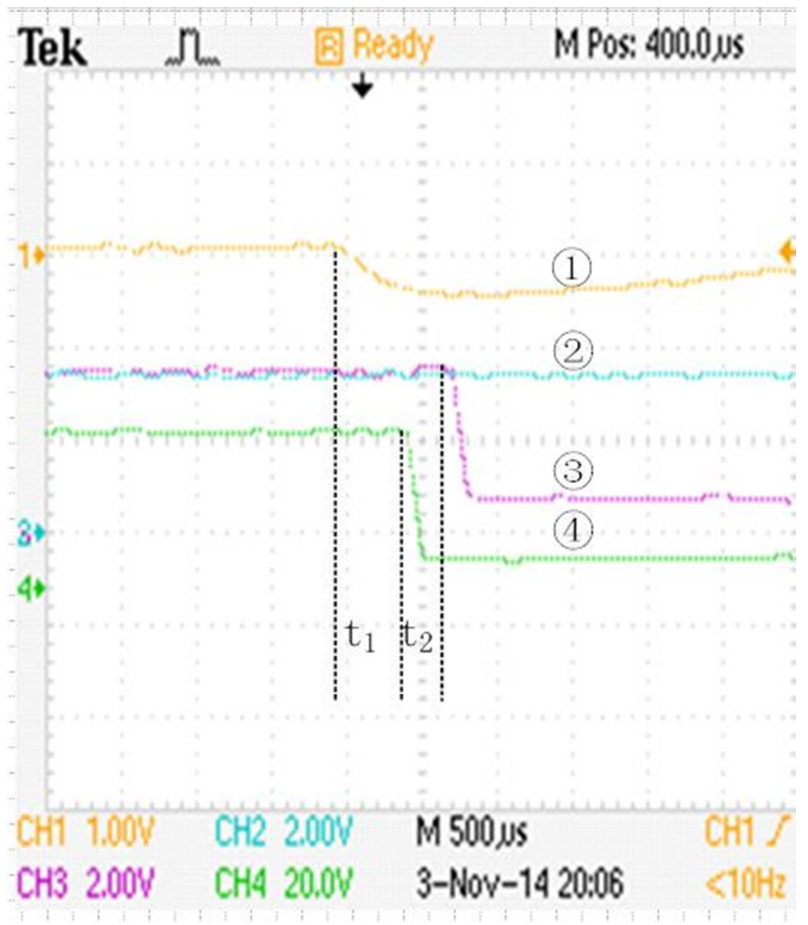

(b) Partial enlarged drawing

Fig. 7. Waveform of protector $S 2$ removing short fault.

Seen from the waveform of "A" phase current, the peak of current is $19.82 \mathrm{~A}$, initial current rising rate up to $15.24 \mathrm{~A} / \mathrm{ms}$. Rise rate judgment setting value of $\mathrm{S} 4$ and $\mathrm{S} 2$ is still $14.85 \mathrm{~A} / \mathrm{ms}$.

In Fig. 7(b), $t_{1}$ is the interval time from initial time of short-circuit to the time second and third level protector completed communicating, it is about $400 \mu \mathrm{S}$. Within $\mathrm{t}_{1}$, the second and third level protector S2 and S4 completed current detection and fault judgment according to rising rate at the same time, third level protector do not tested short current and send the judgment result to the second level protector S2.second and third level protector completed communicating. $t_{2}$ is the interval time from the second and third level protector completed communicating to the time second level protector output the release action and control signal, it is about $200 \mu \mathrm{s}$. Within $\mathrm{t}_{2}$, the second level protector combines received judgment result from $\mathrm{S} 4$ with judgment result itself, reach to the needing action to remove fault according to communication cooperation strategy, outputting release action and control signal, thus the third waveform appears lower jump.

Experiment result tested the correctness and effectiveness of protection system according to communication cooperation strategy when the second and third level protector appears short fault. In a family way, because the chosen protector release executes some responses slowly in experiment, short current cannot be switch-off immediately after release input control signal, this lead to switch-off the short current after 75 $\mathrm{ms}$, but thinking that we mainly research selective protection strategy, action speed of the switches will not affect the test of protection strategy. 


\section{Conclusions}

Aimed at the question that it usually appears upper and lower levels protector switch-off at the same time when the short current is big, we present the ship distribution network selective protection method based on communication cooperation strategy. Giving a specific coordination strategy of each level protector aimed at distribution network of three levels. Completing the design of the structure of ship distribution system protector based on communication cooperation strategy, completing setting up hardware platform. The experimental result tested the effectiveness of communication cooperation strategy. Experiment test result reached that the ship distribution network selective protection method based on communication cooperation strategy is correct and effective. We carry out further research in the terms below: (1) In the context that ensure the correctness of test and judgment, we wish to increase the speed of communicating processing. (2) We wish to find a kind of breaker and contactor that response rapidly to increase the speed of fault switch-off.

\section{Acknowledgements}

This article is one of phased achievement of NSF "Coordination protection method of ship integrated power system based on multi-agent" (51207165).

\section{Reference}

[1] Liu Qiang. Technology discussion of smart power grid relaying [J]. Jiangsu electrical engineering, 2010(02): 82-84.

[2] Jiang Xiaoping, Zhang Peng. Design of smart relaying protector $[\mathrm{J}]$. Association for science and technology BBS, 2011(11), 23-24.

[3] Ji Luming, Zhang Huailiang. Research of ship power distribution network structure [J]. Ship engineering, 2009(02): 35-38.
[4] Li lin, Shenbing, Zhuang Jinwu. Ship power system [M]. WuHan: The tides press. 2003.

[5] Yang Hu. Ship power system microcomputer protection and monitoring system research [D]. Wuhan: Huazhong university of science and technology, 2007, 06.

[6] Mihnko B D, Zoran M. Digital signal processing algorithm for arcing faults detection and fault distance calculation on transmission lines $[\mathrm{J}]$. electrical power and energy system, 2001, 19(3): 165-170.

[7] Zhang Yongwen, Zhong Xiaoming. The selective protection of technology of low voltage power distribution system [J]. Electrical technology, 2007(09): 59-64.

[8] Amann N P. A Development of an adaptive protection scheme for shipboard power systems [D]. Mississippi State Univ, 2007.

[9] $\mathrm{BO} Z \mathrm{Z}$ Q. A daptive non-communication protection for power lines BO scheme the delayed operation approach [J]. IEEE Transaction on Power Delivery, 2002, 17(1): 85-91.

[10] Ding Yixian, Zhao Ruifeng, Le ying. The selective protection of intelligent power distribution system [J]. Low voltage electrical appliances, 2013(08): 44-47.

[11] Feng Zongheng. Low voltage power distribution system selectivity and equipment selection of over-current protection [J]. Electrical engineering application, 2003(4): 17-23.

[12] Tu Jian, Zhang Xianhe, Liu Jinhua. [J]. Based on wavelet transform is the traveling wave ranging and protect the selective research of implementation Coal mine safety, 2009(11): 57-60.

[13] Yin Xianggen, Wang Yang, Zhang Zhe. Zone-division and tripping strategy for limited wide area protection adapting to smart grid [J]. Proceedings of the CSEE, 2010, 30(7): 1-7 (in Chinese).

[14] Shi Ji. The electric power communication and its application in the smart grid [J]. Digital Technology and Application. 2012(06): 50-51. 